\title{
Apéndices masoréticos en manuscritos bíblicos españoles
}

\author{
María Teresa Ortega Monasterio * \\ ILC - CSIC
}

\begin{abstract}
Existe un importante corpus de manuscritos hebreos bíblicos hispánicos datado entre los siglos XII y XV. Estos manuscritos contienen información masorética de diversas categorías: masoras parva, magna, finalis, o bien apéndices masoréticos, ya sean ornamentales o no. Hasta el momento, estos manuscritos han sido estudiados desde un punto de vista textual, es decir, mediante ediciones críticas de sus textos y masoras o de forma comparativa entre ellos. Sin embargo, los estudios comparativos sobre los contenidos masoréticos y sus características especiales son escasos. En este artículo se analizan algunas de estas listas masoréticas contenidas en una selección de manuscritos españoles escritos en la misma época, comparando sus similitudes y discrepancias, prestando especial atención a los apéndices masoréticos, las masoras ornamentales y sus textos.
\end{abstract}

Palabras ClaVE: Masora; apéndices masoréticos; manuscritos hebreos españoles; Biblia.

Masoretic Appendices in Spanish Bible Manuscripts.- There is a significant corpus of Spanish Hebrew manuscripts of the Bible dated $13^{\text {th }}-15^{\text {th }}$ centuries. These manuscripts do all contain Masorah in its different categories: parva, magna, finalis or Masoretic lists being it ornamental or not. So far, these manuscripts have been studied from a textual point of view, either critical editions of their texts or Masorah, or textual comparative studies. However, comparative studies on the specific characteristics of the Masoretic contents and, moreover, a comparison of the different manuscripts from this specific perspective, are scarce. In this paper, I intend to analyse some of these Masoretic lists, by comparing a selection of the most prestigious Spanish Bible manuscripts, their similarities and discrepancies. Furthermore, I will present under scrutiny some of the so-considered ornamental Masorahs and their texts.

KeYwords: Masorah; Masoretic lists; Spanish Hebrew Manuscripts; Bible.

La tradición textual española de los manuscritos bíblicos hebreos está sobradamente probada. Importantes manuscritos producidos en España forman parte de las mejores colecciones en las mayores bibliotecas del mundo y han servido de base para las más prestigiosas ediciones de la Biblia, como la Políglota Complutense, dirigida por el Cardenal Cisneros, o la Biblia Regia, liderada por Arias Montano.

Los estudios que se han hecho hasta el momento sobre estos manuscritos han versado tanto sobre su texto como sobre sus masoras, siendo generalmente edicio-

*rmaite.ortega@cchs.csic.es 
nes críticas o estudios textuales comparados. Pero pocas veces nos hemos detenido a compararlos entre sí, sobre todo, desde el punto de vista de su época de composición o de sus masoras y apéndices masoréticos. Por otra parte, es prácticamente imposible hacer una comparación exhaustiva, dado el alto número de manuscritos existentes: solamente en las bibliotecas de Madrid hay más de 33 españoles completos de la Biblia, y eso teniendo en cuenta que es una de las colecciones más escasas. Pero hemos creído conveniente ofrecer una primera visión general de algunos de los más destacados para tener una primera impresión de los contenidos que se incluyen en sus masoras ornamentales o en sus apéndices masoréticos, señalando algunas características comunes así como algunas peculiaridades.

Desde el punto de vista ornamental, existen ya algunos estudios hechos específicamente sobre estos manuscritos, incluso clasificándolos por áreas de escritura ${ }^{1}$. Esto no impide que en otros trabajos más generales se venga a tratar también de los manuscritos españoles de forma esporádica. Sin embargo, dada la larga tradición de estudios sobre ellos, creo que podemos ofrecer una panorámica más general y comparativa de estos códices. Para el presente trabajo hemos seleccionado los siguientes manuscritos completos de la Biblia, teniendo en cuenta tanto su fecha de composición, como calidad textual avalada por estudios anteriores, así como el hecho de contener, bien masora ornamental curiosa, bien apéndices masoréticos extensos:

- Héb. 25 de la Bibliothèque National de France $[=\mathrm{BnF}]$, copiado probablemente en Toledo en 1232 por Israel Casares ${ }^{2}$ escrito a dos columnas conteniendo al principio listas masoréticas, con masoras ornamentales con micrografías.

- Or. 2201 de la British Library: copiado en Toledo en 1300, escrito en tres columnas, con listas y apéndices masoréticos. Fue utilizado por Ch. D. Ginsburg, tanto para su Introduction to the Massoretico-Critical Edition of the Hebrew Bible, como para su The Massorah Compiled from Manuscripts ${ }^{3}$.

1 T. Metzger, «La Masora ornementale et le décor calligraphique dans les manuscrits hébreux espagnols au Moyen Age», en La Paléographie Hébraïque Médievale (Paris 1972), págs. 87-113.

2 El colofón del fol. 397r da solamente el nombre de Israel. En una nota del fol. 397v se dice que la biblia ha pasado a manos del nieto del escriba y más adelante escribe que es Israel, hijo de Moisés, hijo de Casares. Es decir, el escriba es Israel ben Casares. Agradezco esta información a mi colega F. J. del Barco del Barco que está preparando el catálogo de manuscritos hebreos bíblicos de la BnF. Este dato corrige la descripción de este manuscrito en G. SEd-Rajna, Les Manuscrits Hébreux Enluminés des Bibliothèques de France (Leuven - Paris 1994), págs. 5-7 y M. GAREL, D’une main forte: Manuscrits hébreux des collections françaises (Paris 1991), pág. 59.

New York 1966 y 1975, respectivamente. Su descripción puede verse en las págs. 667-674 de la primera de estas dos obras. Posteriormente a esta descripción se ha aceptado que su fecha de 
- Héb. 22 de la BnF: copiado probablemente en Castilla entre 1270 y 1280 . Escrito a tres columnas, con micrografías y listas masoréticas ${ }^{4}$.

- Héb. 26 de la BnF: copiado en Toledo en 1272 por el copista Hayyim ben Israel. Escrito a tres columnas, contiene numerosas listas masoréticas ${ }^{5}$.

- Parma 2668 (De Rossi 782) de la Biblioteca Palatina de Parma: copiado por Hayyim b. Israel en Toledo en 1277. Escrito a tres columnas, con numerosas iluminaciones y masoras ornamentales. Debido a su alta calidad textual, fue utilizado, como modelo de manuscritos sefardíes, por Y. S. de Norzi para la composición de su Minḥat Šay ${ }^{6}$.

- M1 de la Biblioteca de la Universidad Complutense de Madrid, copiado en Toledo en 1280 por un copista desconocido, con tres columnas por página. Utilizado para la composición del texto de la Políglota Complutense y procedente de la colección de Alfonso de Zamora. El texto de sus masoras, parva y magna, está siendo editado por el equipo de trabajo de Biblia Hebrea del CSIC de Madrid, habiéndose publicado hasta la fecha las correspondientes al Pentateuco y sus apéndices masoréticos. También ha sido objeto de numerosos estudios parciales sobre su texto ${ }^{7}$.

Los dos manuscritos siguientes se han utilizado exclusivamente para los ejemplos que se ofrecen sobre los contenidos de la masora. Por ello se han incluido aunque su fecha de composición sea algo más tardía:

- Héb. 20 de la BnF: copiado en Tudela en 1300. Escrito a tres columnas con abundantes micrografías ${ }^{8}$.

- Héb. 30 de la BnF: copiado en 1357 probablemente en Cataluña. Escrito a tres columnas por página, contiene masoras ornamentales muy variadas ${ }^{9}$.

copia es 1300 en lugar de 1246 como señalaba ese autor. Véase B. NARKISS, Hebrew Illuminated Manuscripts in the British Isles. Part One: Text (Jerusalem 1982), pág. 21.

4 Para una descripción de este manuscrito, véase SEd-RAJnA, Les Manuscrits Hébreux, págs. 15-17 y Garel, D’une main forte, pág. 51.

5 Para más información, véase GAREL, D’une main forte, págs. 44-45.

6 Para si descripción, véase B. RichleR, Hebrew Manuscripts in the Biblioteca Palatina in Parma (Jerusalem 2001), pág. 3.

7 Para una descripción de este manuscrito y amplia bibliografía sobre los estudios sobre su texto y masoras, véase F. J. DEL BARCo Del BARCO, Catálogo de manuscritos hebreos de la Comunidad de Madrid. Vol. I (Madrid 2003), págs. 109-112.

8 Para una descripción de este manuscrito, véase Sed-RAJnA, Les Manuscrits Hébreux, pág. 35-44 y GAREL, D’une main forte, págs. 66-67.

9 Para una descripción de este manuscrito, véase SED-RAJNA, Les Manuscrits Hébreux, págs. 56-58 y GAREL, D’une main forte, pág. 54-55. 
Dentro de este grupo de 8 manuscritos, podemos apreciar que seis de ellos están fechados en el siglo XIII y dos en el XIV. Todos ellos son hispanohebreos ( 5 de ellos fueron escritos en Toledo, uno en Castilla, uno en Cataluña y el último en Tudela), e incluso dos de ellos pertenecen al mismo copista. Sería, por tanto, de esperar, un alto grado de similitudes, por lo menos en el contenido de sus listas y apéndices.

\section{APÉNDICES MASORÉTICOS}

La masora tiene una larga historia. Surge por la necesidad de fijar una serie de reglas gramaticales necesarias para la correcta lectura del texto bíblico y, poco a poco, se va convirtiendo en una parte esencial de los manuscritos, en un «segundo texto» para el que incluso se reserva un espacio determinado en el momento de diseñar la disposición de cada página. El copista es consciente de la importancia de la masora y, cada vez más, se le concede un lugar en el manuscrito, un protagonismo que, gracias a la introducción y evolución de la micrografía, llega a ser de gran relevancia a partir del siglo XIII. En los manuscritos hebreos, el escriba de la masora es también el responsable de las micrografías. Algunos autores, como Narkiss ${ }^{10}$, atribuyen también al masoreta la vocalización del manuscrito pero, en algunos casos, se aprecia claramente que se trata de dos personas distintas.

Los manuscritos conservados copiados en las etapas tempranas (siglos X-XI), generalmente procedentes del Mediterráneo oriental, tienen unas masoras de apariencia sencilla, salvo algunas excepciones como pueden ser los llamados códices de El Cairo y Leningrado. Excepto las páginas dedicadas especialmente a micrografías o páginas tapiz, la masora que se escribe junto al texto del manuscrito no presenta dibujos, exceptuando algunas figuras geométricas muy sencillas.

Precisamente esas páginas tapiz son las que se utilizan para recoger las listas masoréticas que en ese momento se consideraban importantes, copiadas generalmente de los primeros tratados masoréticos como el Sefer Oḱklá we-Oklá, Diqduqé ha-Te 'amim u otros similares.

Pero con el paso del tiempo, llegamos a manuscritos del siglo XV en los que la micrografía se convierte en parte integrante de las anotaciones marginales del manuscrito: no solamente aparece en las páginas tapiz, sino que forma parte de la decoración de muchas de sus páginas, llegando a formar complicadísimos dibujos. Hay que tener en cuenta que, aunque en el tratado Soferim del Talmud se dan las reglas que se deben seguir para escribir los rollos de la Torá ${ }^{11}$, las reglas para escribir los

10 B. NARKISS, «The Relation between the Author, Scribe, Massorator and Illuminator in Medieval Manuscripts», en La Paléographie Hébraïque Médiévale (Paris 1974), págs. 79-84.

11 Soferim II, 35b y III 36a. 
códices son mucho más permisivas, por lo que es comprensible que las micrografías adoptaran mayores licencias. Generalmente, las formas que toman nada tienen que ver con su contenido ${ }^{12}$ que, en la mayoría de los casos, sigue siendo material masorético, aunque a veces, como veremos más adelante, se incorpora otro tipo de información. En toda esta evolución, las páginas tapiz han pasado de tener un contenido exclusivamente masorético a tener un contenido más variado: han dejado de tener la finalidad primera que se les dio en los manuscritos más tempranos. Estas micrografías, junto con las que aparecen en los márgenes de los textos, pueden considerarse en sus fases más perfeccionadas como verdaderas obras de arte ya que suponen un hito en las decoraciones de los manuscritos al mismo tiempo que una característica muy especial de los manuscritos hebreos.

Precisamente tenemos un buen ejemplo de esta evolución en los manuscritos españoles de los siglos XIII y XIV. En ellos, podemos encontrar micrografías abundantes y, en la mayoría de los casos, su contenido es estrictamente masorético, con algunas excepciones a esta norma. Este texto contenido en la micrografía muchas veces resulta casi imposible de leer, pasando a ser su primera finalidad la decorativa y restando importancia al contenido. Esta teoría ha sido defendida por investigadores como Colette Sirat ${ }^{13}$. Entre las Biblias procedentes de Toledo se han establecido algunas características comunes respecto a este tipo de páginas, como es el marco formado por un texto en hebreo encuadrando las listas masoréticas. Estos textos están compuestos en su mayoría por versículos bíblicos o notas citando el nombre o algún otro detalle sobre el copista. Frecuentemente el marco es de forma cuadrada o rectangular. Sin embargo, en algunos casos está inspirado en motivos arquitectónicos, que también recuerda a los motivos utilizados en algunos manuscritos árabes de la Península. También los motivos utilizados en las micrografías se repiten con cierta frecuencia.

Hasta el momento, las micrografías de estos manuscritos han sido objeto de estudios parciales desde el punto de vista de la decoración, pero nunca desde el punto de vista de su contenido ${ }^{14}$. Si en esos estudios ya han sido establecidas

12 Ver, por ejemplo, S. FERBER «Micrography, a Jewish Art Form», Journal of Jewish Art 3-4 (1976-77), págs. 12-24.

13 C. SiRat-L. Avrin, La Lettre hébrä̈que et sa signification. Micrography as Art (ParisJerusalem 1981), pág. 18.

14 Ver, por ejemplo, los estudios de G. SED-RaJnA, «Hebrew Manuscripts from Toledo and Tudela: Creation or Transmission?», en Abraham Ibn Ezra y su tiempo, ed. F. Díaz Esteban (Madrid 1990), págs. 301-307; T. MetzGer, «La Masora ornementale et le décor calligraphique dans les manuscrits hébreux espagnols au Moyen Age», en La Paléographie Hébraïque Médiévale (Paris 1974), págs. 87-113. 
algunas similitudes, voy a intentar establecer otras teniendo en cuenta la disposición y contenido de las listas y apéndices. Vamos a ver a continuación los contenidos que presentan las listas masoréticas de estos manuscritos y alguna de las peculiaridades que presentan en sus micrografías ${ }^{15}$.

\section{Héb. 25 de la BnF}

Al principio y al final del manuscrito hay varios folios dedicados a listas masoréticas, además de las micrografías que aparecen en los fols. 8v, 9r-10r, 40r y v, 108r. Según la descripción del manuscrito estas decoraciones han sido hechas por la misma mano que ha copiado la masora ya que tiene la misma tinta. Sin embargo, el manuscrito presenta además una micrografía en el fol. 30v hecha posteriormente. Los motivos que aparecen son geométricos, en forma de cordones entrelazados sin fin y enmarcando el texto bíblico.

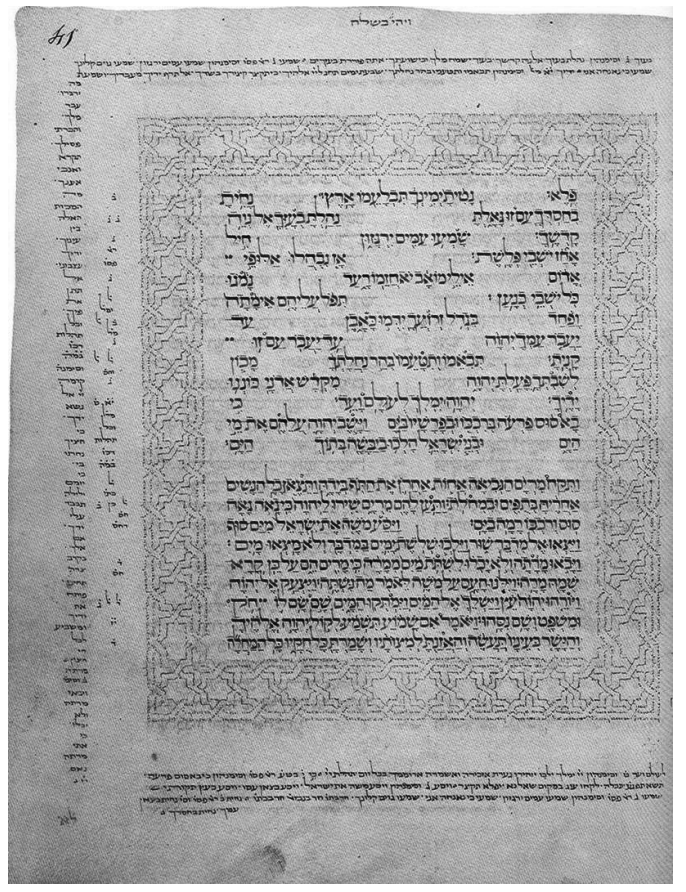

Fig. 1. Héb. 25, BnF, fol. 45r.

15 Para este estudio se han consultado los manuscritos originales conservados en la BnF y en la biblioteca de la Universidad Complutense. No fue posible en el caso del Or. 2201 de la BL, por encontrarse el manuscrito en proceso de restauración, ni para el 2668 de la Biblioteca Palatina de Parma. En estos casos se ha trabajado con el microfilm existente en el ILC del CSIC. 
Dada la similitud de las decoraciones de este manuscrito con las de otros datados en Toledo, parece que también procede de allí. Concretamente, el Or. 2201 contiene micrografías que siguen el mismo modelo que algunas del Héb. 25, las que rodean el texto de Ex 15 en ambos manuscritos. En el colofón del fol. 397r-v se nombra al copista Israel Casares En Toledo existía la famosa familia de copistas de apellido Israel, a la que pertenece Hayyim ben Israel, que aparecerá más adelante, pero no está probado que nuestro copista estuviera emparentado con ellos, aunque así lo sugiere Sed-Rajna ${ }^{16}$.

El primer bloque de información masorética está formado por los siguientes contenidos:

Los fols. $1 \mathrm{v}$ a $7 \mathrm{v}$ constituyen un cuaderno añadido al manuscrito, lo mismo que el bifolio formado por los fols. 398r a 399v. Este primer cuaderno contiene varias listas masoréticas de contenido litúrgico: parašiyyot y haftarot del Pentateuco, lista de parašiyyot y haftarot que se leen en las distintas fiestas como Pésaḥ, Šabu 'ot, Roš ha-Šaná, etc., número de parašá en la que empieza cada libro de la Torá, lista de parašiyyot que se leen en Sucot, en šabbat, en Roš Hodeř, etc.

El fol. 8r lo ocupa un poema introductorio escrito en cinco líneas seguidas, rodeado de decoración formando un dibujo geométrico. Esta decoración ocupa el espacio que estaba destinado a micrografía, como se puede apreciar en el manuscrito original por el pautado.

El fol. 8v está ocupado por un colofón rodeado de micrografía. El contenido de esta micrografía no es masorético. Se trata de texto bíblico de los libros de Génesis, Números, Levítico, Jueces, Job, Proverbios y Crónicas ${ }^{17}$ y varias alabanzas.

Los fols. 9r a 10r están ocupados por listas de estricto contenido masorético: listas de palabras que lleven en medio un yôd que debe leerse como waw (Ochl 80) ${ }^{18}$, y su contraria, lista de palabras que llevan en medio un waw que debe leerse yôd (Ochl 81), lista de 62 palabras que alteran el orden de dos letras (Ochl 91), lista de 20 palabras que terminan en hê muda precedida de kaf (Ochl 92), y lista de 5 grupos de 3 palabras que escriben una palabra que debe leerse de forma distinta, lista de 5 pares de palabras que escriben hê al final una vez y la otra escriben yôd (Ochl 94), lista de 12 pares de palabras que escriben alef al final una vez y la otra escriben hê (Ochl 95), diez letras con puntos en el Pentateuco, cuatro en Profetas y una en Hagiógrafos.

16 Sed-Rajna, Les Manuscrits Hébreux, pág. 7.

17 Gé 30:40; Le 4:33; Nú 46:27; Ju 5:24-26; Job 1:1, 5:27, 17:9, 29:4, 33:33, y 38:35; Pr 5:11, $9: 11,14: 4,18: 10,22: 21$, y 25:13; y 2Cr 20, entre otros.

18 Se indica entre paréntesis la lista que le corresponde en S. FrensdorfF, Das Buch Ochlah W'Ochlah (Hannover 1864), en ocasiones de forma aproximada en cuanto a los casos reseñados. 
El segundo bloque de información masorética aparece al final del Pentateuco, en el fol. 108r. Contiene lista de 10 palabras que se leen y no se escriben (Ochl 97), y su contrario, lista de palabras que se escriben y no se leen (Ochl 98), 15 palabras que se escriben en una palabra pero se leen como dos (Ochl 99), y su contrario, lista de 8 palabras que se escriben en dos pero se leen como una sola (Ochl 100), 3 pares de palabras cuya última letra de la primera palabra es la que debería ser la primera de la palabra siguiente (Ochl 101), y su contrario, dos pares de palabras en las que la segunda palabra empieza con la letra que debería ser la última de la primera palabra (Ochl 102), 12 palabras que se escriben con alef a final de palabra pero que no se lee (Ochl 104), 15 ocasiones en las que se escribe לא pero se debe leer לchl 105).

El tercer bloque que se inserta al final de Profetas Menores, a partir del fol. $287 \mathrm{v}$, también contiene listas masoréticas escritas en el espacio que debería ocupar la segunda columna del texto bíblico. Se trata de una lista de 29 palabras a las que les falta un hê al final (Ochl 111).

Este manuscrito presenta, por lo menos, tres manos distintas. En la masora o micrografías se distinguen claramente dos. Ejemplos de otra mano son un recuadro de micrografía en forma geométrica de entrelazados sin fin, con contenido masorético rodeando el texto de Ex 15 (fols. 40v a 41r) o una micrografía ornamental que aparece en el margen inferior del fol. $30 \mathrm{v}$, también de contenido masorético.

\section{Or 2201 de la British Library}

Los primeros folios del manuscrito, pero sobre todo los últimos de cada bloque de libros bíblicos, contienen numerosas listas masoréticas. En el colofón (fol. 184r) se dice que fue terminado de copiar en el mes de iyyar de 1300 en Toledo por Yosef ben Yehudá ben Merwás. Su masora ornamental es muy sencilla, rodeada por texto en letras de mayor tamaño generalmente formando círculos, rombos o incluso la «estrella de David» inscrita en un círculo (fol. $99 v)$. La masora magna, en el caso de hacer dibujos, lo hace en forma de semicírculos o zig-zag. La decoración del manuscrito ha sufrido mucho el paso del tiempo y está muy deteriorada, sobre todo el fol. $2 \mathrm{v}$ que reproduce los objetos del Templo.

En cuanto al contenido de las listas masoréticas es como sigue ${ }^{19}$, dividido en tres bloques: el primero, al final del Pentateuco; el segundo al final de los

19 El contenido que aquí se describe corrige tanto a G. Margoliouth, Catalogue of the Hebrew \& Samaritan Manuscripts in the British Museum, págs. 21 ss. como a GinsBurg, Introduction, págs. 667ss. Tampoco se corresponde exactamente con la ofrecida por MetzGER, «La Masora ornamentale». 

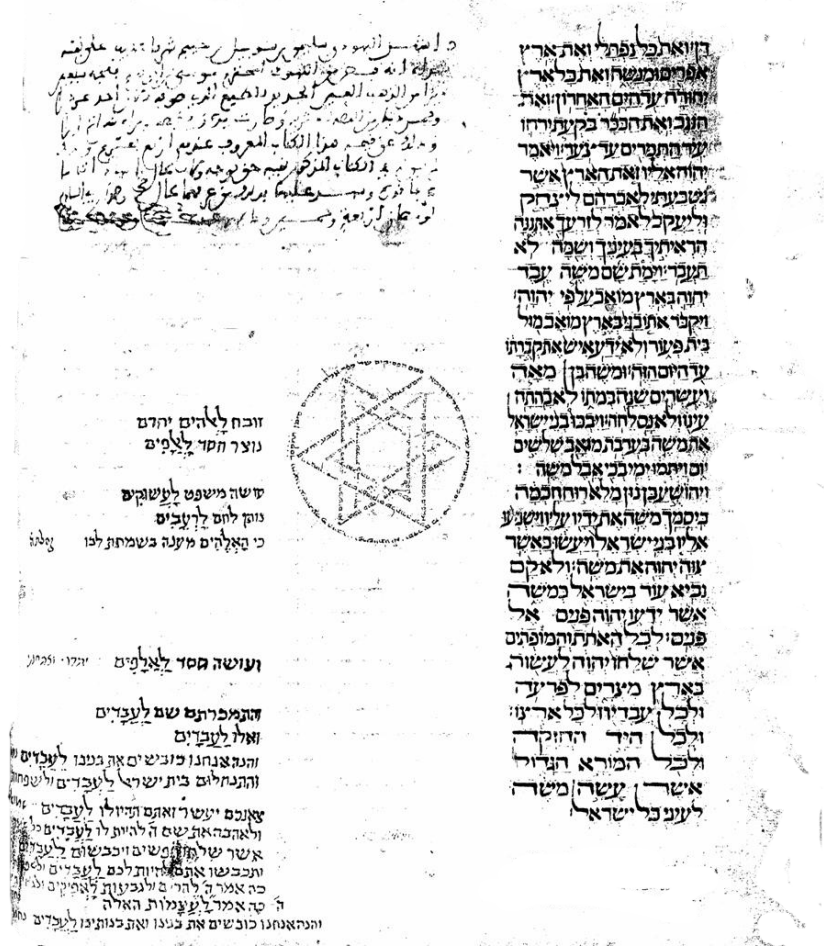

Fig. 2. BL, Or. 2201, Final de Deuteronomio, fol. 99v. (C) British Library Board. All Rights Reserved.

Profetas Primeros y el tercero al final de los Hagiógrafos, con otra lista que aparece en el último folio del códice.

Primer bloque:

Fol. 2v a 3r contiene la lista de sedarim del Pentateuco.

Fol. 3r: la lista de casos que tienen pataḥ con atnạ̣ o sôf pasûq en el Pentateuco; lista de palabras que se escriben como tres y se leen como una.

Fol. 3v: lista de 20 casos de palabras que terminan en hê que no se lee (Ochl 112): lista de 20 casos a los que les falta un hê a final de palabra que debe leerse (Ochl 111); lista de cuatro pares de palabras que aparecen dos veces, la primera escrita con alef y la segunda sin alef(Ochl 200); lista de 5 palabras que terminan en mem que no debe leerse (Ochl 156); lista de 5 palabras a las que les falta un mem al final que debe leerse (Ochl 157). 
Segundo bloque:

Fol. 99v: micrografía en forma de estrella de seis puntas inscrita en un círculo con recuento de versículos, parašiyyot y letras en los libros del Pentateuco.

Fol. 100r a 101v: lista de hill·lufìm Ben Ašer / Ben Naftalí del Pentateuco.

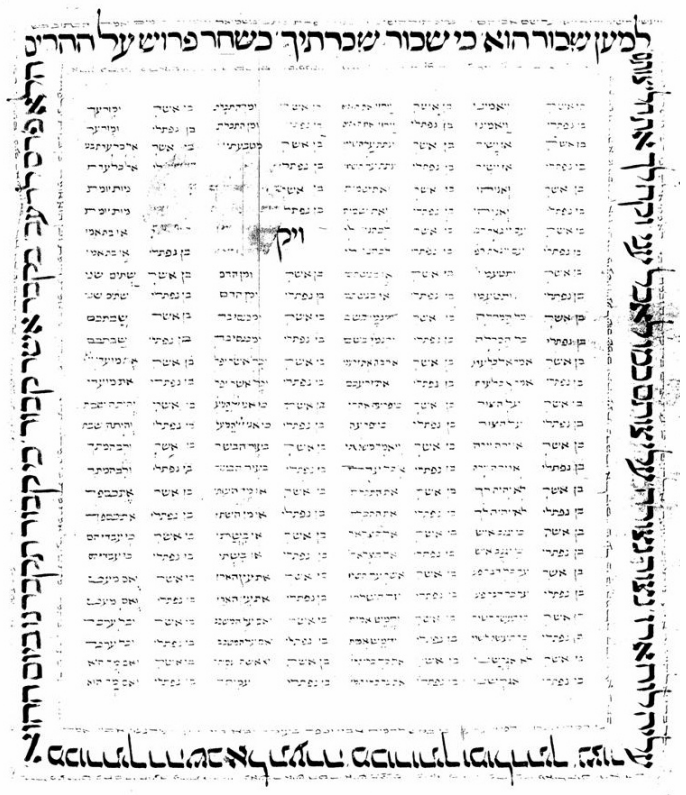

Fig. 3. BL, Or. 2201, fol. 100v. (C) British Library Board. All Rights Reserved.

Resto del fol. 101v: cronología del Pentateuco.

Fol. 102r: la lista (sin encabezamiento) de casos que tienen pataḥ con atnaḥ o sôf pasûq en los libros Emet ${ }^{20}$, las cinco megil·lôt, Daniel, Esdras y Nehemías.

Fol. 102v a 103v: Sefer Ha-Te 'amim de Aharón ben Ašer. Este texto reproduce parte de la lista de Ginsburg, Massorah, vol. I, טעמים, lista 246, § 1-5, con alteraciones en el orden (el § 2 aparece en último lugar).

Resto del fol. 103v a 104r: lista alfabética de casos que aparecen dos veces solamente y en el mismo versículo (Ochl 58); lista alfabética de palabras que aparecen en la Biblia con la misma forma y distinto significado (Ochl 59).

20 Salmos, Proverbios y Job. Es la forma de referirse a ellos basándose en las iniciales de sus nombres en hebreo. 
Tercer bloque:

Fol. 184v: lista de letras más grandes, letras más pequeñas y tres con nûn pequeño; lista de 15 palabras marcadas con un punto en la Biblia: diez en la Torá, cuatro en Profetas y una en Hagiógrafos, lista alfabética de palabras que aparecen dos veces, una con pataḥ y otra con qameș.

Fol. 337v: lista de palabras que tienen patạ̣ con atnaḥ o sôf pasûq en los Hagiógrafos y en Crónicas. Esta lista ocupa el espacio de dos de las columnas de texto y continúa en la lista del fol. 102r.

\section{Héb. 22 de la BnF}

Esta Biblia, datada hacia finales del siglo XIII y copiada probablemente en Castilla, está escrita a tres columnas con masoras parva y magna, dispuestas de la forma acostumbrada. Tiene tres bloques de información masorética al principio, al final del Pentateuco y al final del manuscrito, aunque incluye, al final de los libros bíblicos, otras listas con varios tipos de recuentos formando círculos generalmente (fols. 46v, 59v, 152v o 215v). Al final de Deuteronomio y de Proverbios adoptan otras formas geométricas. Este manuscrito no presenta páginas tapiz.

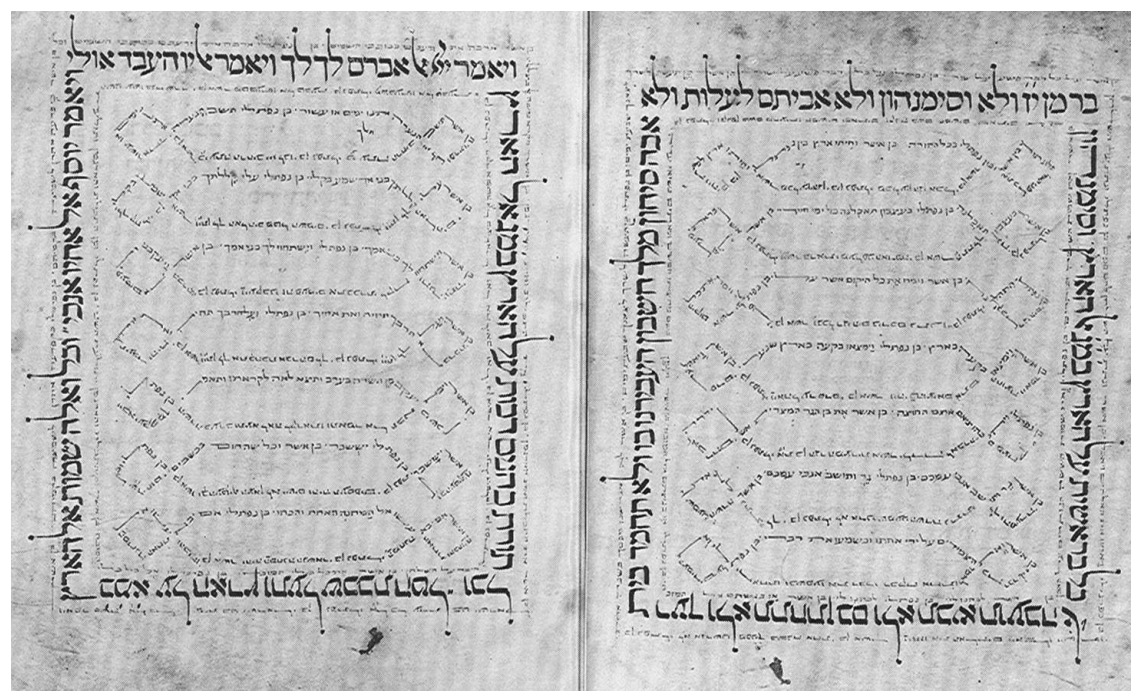

Fig. 4. Héb. 22, BnF, fol. 3v-4r. 
El primer bloque tiene los siguientes contenidos:

Fols. 1v a 2r: lista de sedarim del Pentateuco. Fols. 2v a 3r: lista de paseqîm del Pentateuco. Fol. 3r: lista de casos que tienen patạ̣ con atnaḥ o sôf pasûq en el Pentateuco. Fols. 3v a 4r: lista de hill lufìm Ben Ašer / Ben Naftalí en al Pentateuco, en micrografías de formas geométricas. Fols. 4v a 5r: lista de sedarim en los Hagiógrafos.

Todas estas listas aparecen enmarcadas por un texto en letra de mayor tamaño, rodeada a su vez por otros textos en letras menores.

Segundo bloque, al final del Pentateuco:

Fols. 93v a 96r: micrografías de formas geométricas rodeando el texto bíblico, a una columna (fol. 96r) o a dos en los demás folios. El contenido de las micrografías es masorético, incluyendo listas de casos únicos, excepto en el fol. 96r, en el que se copia el texto de Sal 133:1-3, De 34:12, 34:7 y 34:10, terminando con el recuento de versículos del Pentateuco.

Tercer bloque, al final de la Biblia:

Fols. 376v a 377r: recuento de versículos en Profetas y diversas micrografías.

Fols. 377v a 378r: micrografías en forma de enrejado ocupando toda la página, enmarcada por un texto seguido de mayor tamaño. Contiene listas de grupos de palabras por pares que difieren en la última palabra.

La masora magna de este manuscrito adopta generalmente formas geométricas simples, formando ángulos, enrejados o zig-zag. Quizá debido a esta similitud con algunos manuscritos toledanos podría sugerirse también una procedencia toledana. Las formas que adopta la masora ornamental no son tan complicadas ni forman florones como veremos en M1. En este aspecto, guarda más parecido con Or. 2201.

\section{Héb. 26 de la BnF}

Esta Biblia, fechada en Toledo en 1272 según su colofón (fol. 456v) y copiada por Hayyim b. Israel esta escrita a tres columnas, con masoras parva y magna. Se trata de una Biblia muy sencilla, sus masoras no son ornamentales y no tiene ninguna página tapiz.

Los apéndices que contiene se disponen al final del manuscrito, a partir del fol. $455 \mathrm{r}$ hasta el $459 \mathrm{v}$, aunque falta un bifolio del manuscrito entre $454 \mathrm{v}$ y $455 \mathrm{r}$ y tras 460v. La apariencia de estos apéndices es siempre la misma, en forma de listas encuadradas dentro de un marco escrito con letras de mayor tamaño, rodeado a su vez por otro texto en letra de menor tamaño. Es decir, su disposi- 
ción es igual a la de los manuscritos Or. 2201 y Héb. 22. Su contenido es como sigue:

Fol. 455r: recuento de versículos en los distintos libros de la Biblia. Este folio comienza a mitad del recuento, por faltar un folio delante de él.

Fol. 455v: continuación del anterior.

Fol. 456r: continuación del anterior; lista de versículos que comienzan por en los distintos libros bíblicos y sus excepciones; lista de versículos que comienzan por ואם o אם (similar en parte a Ochl 346).

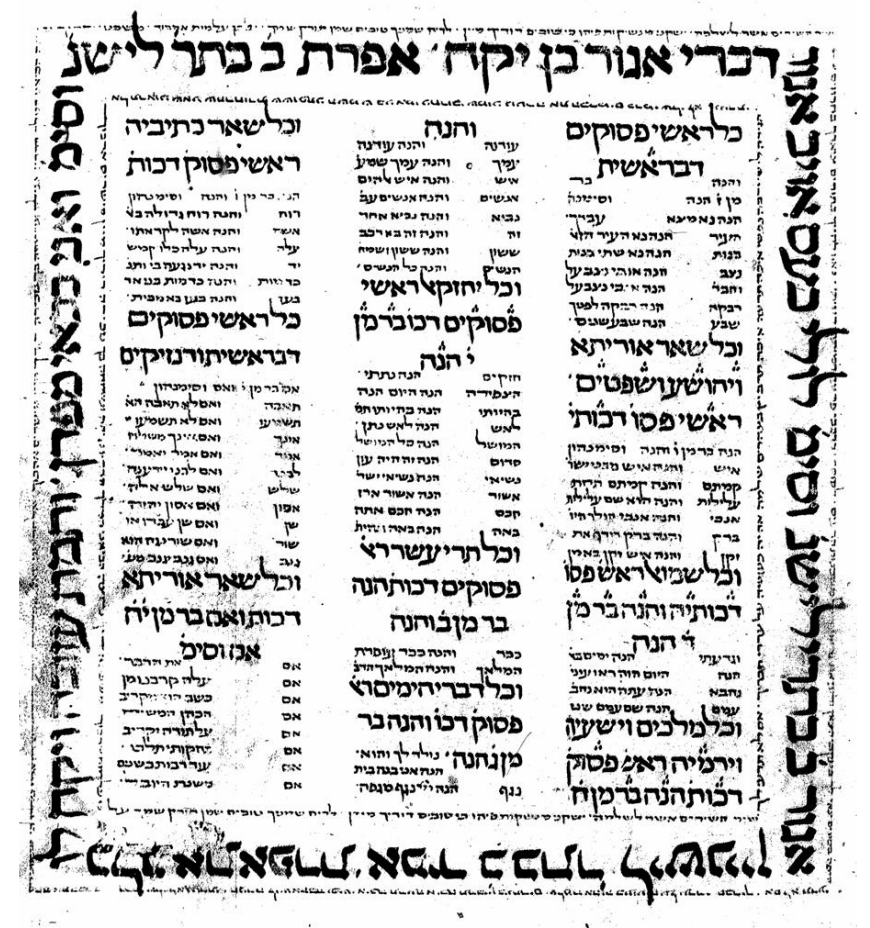

Fig. 5. Héb. 26, BnF, fol. 456r.

Fol. 456v: lista de casos en los que aparece ואם a principio de versículo en los libros de Josué y Jueces; idem en Samuel y Jeremías; y en todo el resto de la Biblia es אם excepto en 11 casos en los que es ואם; ídem con אם לא en Job y Jeremías, con sus excepciones.

Fol. 457r: Listas de uno de los 8 versículos que contienen ואם ואם (Ochl 344); listas de versículos en el Pentateuco, en Josué y Jueces, Samuel, Reyes, Isaías, Jeremías, Ezequiel, Profetas Menores que comienzan con גם 


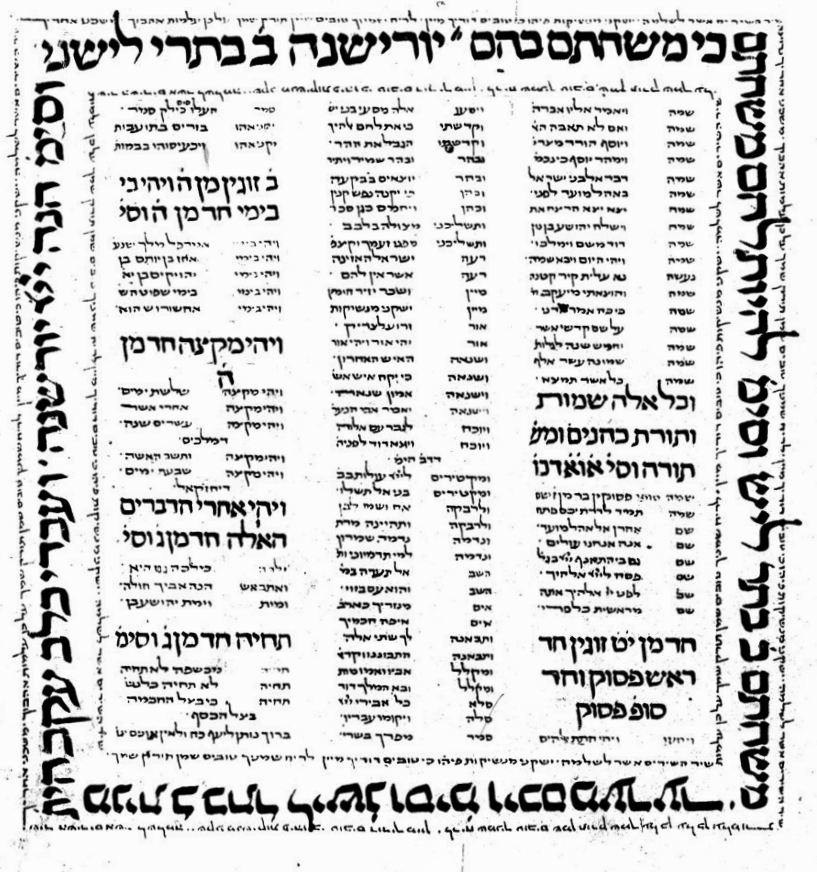

Fig. 6. Héb. 26, BnF, fol. 459r.

sus excepciones; lista de versículos que escriben אנכי o אני con מגם a principio de versículo; lista de versículos en el Pentateuco que comienzan con אלה excepto 17 que comienzan con ואלה.

Fol. 457v: lista de versículos que comienzan con ואלה תלדות y sus excepciones en los libros bíblicos; lista de 14 palabras que aparecen dos veces a principio de palabra con waw; en los demás casos van siempre sin waw (Ochl 172).

Fol. 458r: lista de 12 grupos de palabras que aparecen tres veces con waw a principio de versículo (Ochl 173); a principio de versículo en la Biblia aparece שתתה excepto 25 veces en que es עתה; en Daniel a principio de versículo aparece ארין excepto 13 veces que es ídem en el libro de Esdras, excepto en tres ocasiones.

Fol. 458v: lista de 11 casos que son excepción a la regla que dice que a principio de versículo en la Biblia siempre se escribe זואת menos en estos 11 casos que es וזואת; la palabra ובשנת aparece 10 veces en medio de versículo y 9 al principio; la palabra ומשה aparece 6 veces a principio de versículo; la palabra aparece 3 veces a principio de versículo; la palabra אנכי siempre se escribe así 
en la Biblia excepto en 9 ocasiones en las que es ואנכי; la palabra הם así en la Biblia a principio de versículo, excepto en 9 ocasiones en que es והם la palabra הםה se escribe así a final de versículo excepto en 9 ocasiones que es הם; la palabra שם se escribe así a final de versículo en la Biblia excepto en 18 ocasiones en que es שמה.

Fol. 459r: lista de pares de palabras que aparecen una vez a principio de versículo y otra vez al final; 5 casos en los que aparece ויהי כי בימי 5 casos en los que aparece ויהי מקצה 3 casos en los que aparece 3 ויהי הדברים תחיה Al final aparece una alabanza sobre 3 casos en los que aparece. Is 40,1 .

\section{Parma 2668 (De Rossi 782)}

Obra del mismo copista que el manuscrito anterior, Hayyim b. Israel, esta Biblia está escrita a dos columnas, excepto en los textos poéticos y de los Salmos, que se escriben de la forma acostumbrada. El texto viene acompañado de masoras parva y magna de muy sencillo diseño. No forma micrografías, sino que ocupa las líneas de los márgenes superiores e inferiores y los espacios intercolumnares. Tampoco tiene páginas tapiz, si exceptuamos los fols. 7v y $8 \mathrm{r}$ que reproducen los objetos del Templo. Estas decoraciones tienen gran similitud con las del manuscrito Or. $2201^{21}$.

Los apéndices con contenido masorético se encuentran, sobre todo, al principio del manuscrito, de la siguiente forma:

Fol. 4r: lista de parašiyyot del Pentateuco.

Fol. 4v: continuación de la anterior; lista de haftarot.

Fol. 5r: continuación de la anterior; Lista de hil ·lufîm Ben Ašer / Ben Naftalí en el Pentateuco. (Foto 7)

Fols. 5v a 7r: continuación de la anterior.

Fol. 7v a 8r: decoraciones con los instrumentos del Templo.

Fols. 8v a 12r: el espacio destinado a listas está en blanco. Solamente el fol. $8 \mathrm{v}$ tiene una decoración. Todos conservan únicamente el marco rectangular formado por un texto litúrgico en letras de mayor tamaño. También se mantiene este formato en el resto de las listas masoréticas.

Fol. 12v: lista de casos de qěrê wě-lô kětîb; lista de casos de kětîb wě-lô $q \check{e} r \hat{e}$; lista de 15 palabras que se escriben en una palabra y se leen como dos (Ginsburg, Massorah, vol. II, pág. 54, § 482); lista de 8 palabras que se escriben

21 G. SED-RAJnA, «Toledo or Burgos?», Journal of Jewish Art 2 (1975), págs. 6-21. 


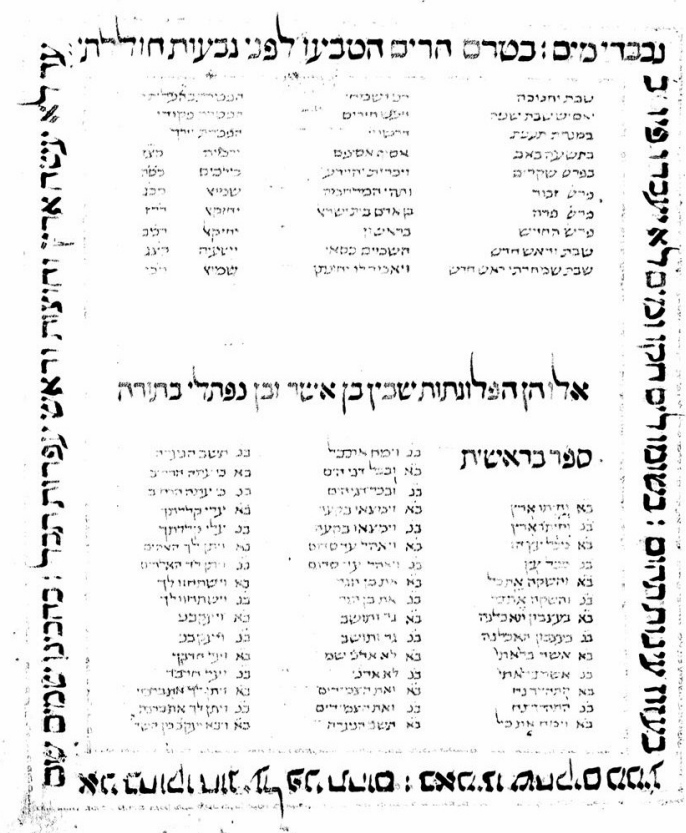

Fig. 7. Parma 2668, BPP, fol. 5r.

como dos y se leen como una sola (Ginsburg, Massorah, vol. II, pág. 54, § 483); lista de tres expresiones en la que la primera palabra toma su última letra de la palabra siguiente; y su contrario, lista de dos expresiones en las que la segunda palabra toma su primera letra de la primera palabra (Ginsburg, Massorah, vol. II, pág. 54, § 485).

Fol. 13r: lista de 48 palabras que tienen un alef en medio de palabra que no se lee (Ginsburg, Massorah, vol. I, pág. 11, lista 18b); lista de 12 palabras que escriben un alef al final (Ginsburg, Massorah, vol. I, pág. 16, lista 20); [...]; y al contrario, que no se escribe y se lee; lista de 13 palabras que no escriben hê a principio de palabra pero se lee; y su contrario, siete palabras escriben hê a principio de palabra y no se lee (Ginsburg, Massorah, vol. I, pág. 256, lista 9).

Fol. 13v: lista de tres palabras defectivas de hê en medio de palabra pero que se lee y su contrario, dos palabras que tienen hê en medio de palabra y que no se lee (Ginsburg, Massorah, vol. I, pág. 268, lista 26); lista de 29 palabras defectivas de hê a final de palabra pero que se lee (Ginsburg, Massorah, vol. I, pág. 269, lista 33); lista de 14 palabras que escriben hê a final de palabra y se lee waw (Ochl 113) y su contrario, lista de 8 palabras que se escriben con waw 
a final de palabra pero se lee hê (Ochl 115); lista de 7 ( $\mathrm{sic}$, son 5) palabras en la misma forma que terminan en hê que debe leerse como waw (Ochl 114).

Fol. 14r: lista de palabras que se escriben con hê o con yôd; lista de 6 palabras que se escriben con yôd al final pero se lee como hê (Ginsburg, Massorah, vol. II, pág. 681, lista 29); lista de 12 palabras defectivas de waw al principio pero que se lee (Ochl 117); y su contrario, lista de 11 palabras que tienen escrito un waw al principio que no se lee (Ochl 118); lista de 12 palabras defectivas de yôd al final pero que se lee (Ginsburg, Massorah, vol. II, pág. 681, lista 28, Ochl 126).

Fol. 14v: lista de 18 palabras defectivas de waw al final pero que se lee (Ginsburg, Massorah, vol. II, pág. 422, lista 146 y Ochl 119); y su contrario, lista de 11 palabras que se escriben con waw pero que no se lee (Ochl 120); lista de 4 palabras que se escriben con het y se leen con hê (Ochl 121); dos palabras que tienen yôd al principio y que no se lee (Ochl 124); y su contrario, palabras que no tienen yôd a principio de palabra, pero debe leerse (Ochl 125); lista de 12 palabras que son defectivas de yôd a final de palabra pero debe leerse (Ochl 126), aunque solamente se reseña un caso; y su contrario, lista de 13 palabras que llevan yôd a final de palabra pero no se lee (Ochl 127).

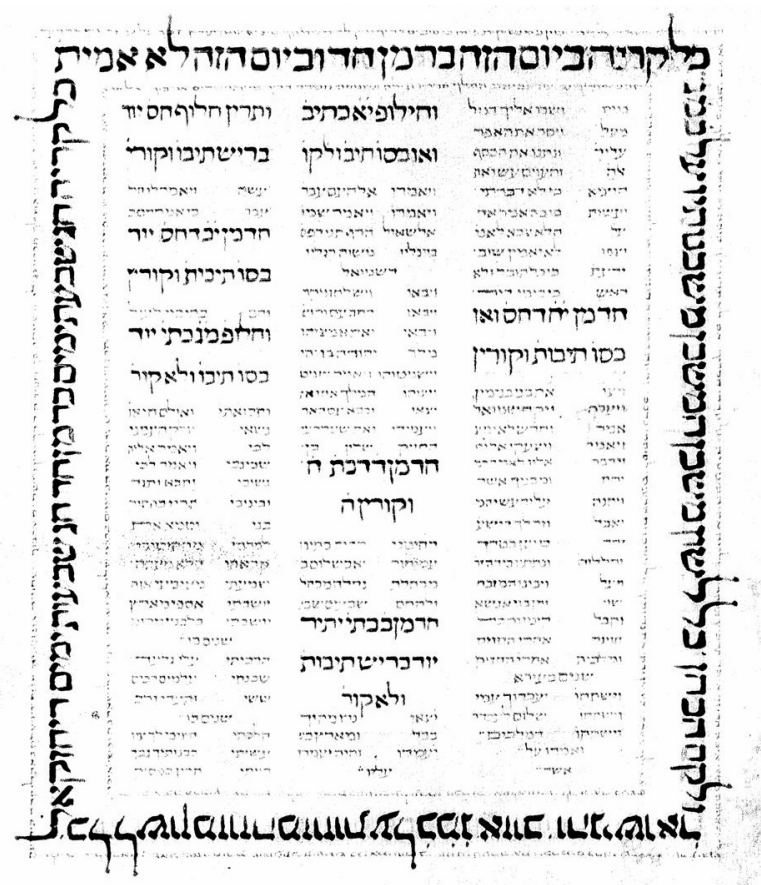

Fig. 8. Parma 2668, BPP, fol. 14v. 
Fol. 15r: lista de 56 palabras defectivas de yôd en medio de palabra pero que debe leerse (Ochl 128); y su contrario, lista de 6 palabras con yôd en medio de palabra pero que no se lee (Ochl 129); lista de 7 ( sic, son 6) palabras que se escriben con yôd a final de palabra que debe leerse como hê (Ochl 116).

Fol. 383r: (con otra mano) listas de parašiyyot de varios libros bíblicos; lista de 31 casos en los que aparece ועל אדני en la Biblia (Ginsburg, Massorah, vol. II, pág. 399, lista 436).

\section{M1 de la Biblioteca de la Universidad Complutense}

Esta magnífica Biblia, copiada en Toledo en 1280 por un copista desconocido, está escrita a tres columnas, con masoras parva y magna con abundantes micrografías, hechas siempre en los márgenes del manuscrito o en el espacio que debía ocupar alguna columna del texto. Las formas que adopta son, bien geométricas sencillas, en el caso de la masora que ocupa los márgenes superior e inferior, o florones en el caso de ocupar los márgenes externos.

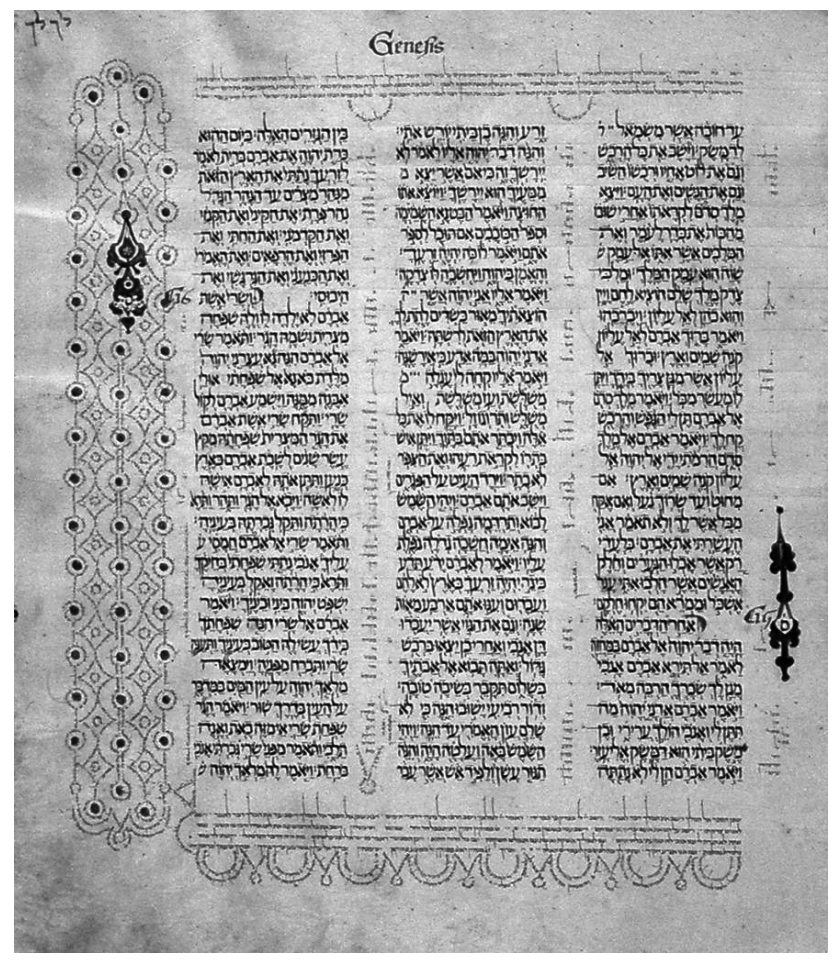

Fig. 9. M1, BUC, fol. 6r. 
El manuscrito no tiene páginas tapiz, pero incluye varios apéndices masoréticos, distribuidos en cuatro bloques y escritos en dos formas distintas: micrografía (fol. 158r) ${ }^{22}$ o texto seguido ${ }^{23}$, distribuido en tres columnas con letra menor que la del texto bíblico pero mayor que la de la masora (fols. $81 \mathrm{r}-82 \mathrm{v}$, 239r-240v y 335v-340v).

El contenido de los apéndices es como sigue ${ }^{24}$ :

Fols. 81r-82v: parašiyyot de los libros del Pentateuco, recuento de versículos, palabras y letras de cada parašá, lista de hilllufím del Pentateuco y listas de qěrê / kètî̉b en todas las parašiyyot del Pentateuco.

Fol. 158r: apéndice en forma de micrografía ornamental conteniendo lista de sedarim de los libros de los Reyes (Ginsburg, Massorah, vol. II, págs 331-332, lista 83); lista de pasequîm de los mismos libros (Ginsburg, Massorah, vol. I, pág. 648-9, lista 208); lista de palabras vocalizadas con pataḥ con atnaḥ o sôf pasûq, también de los libros de los Reyes (Ginsburg, Massorah, vol. II, pág. 301, lista 561 y 562); lista de lecturas variantes entre orientales y occidentales (Ginsburg, Massorah, vol. I, pág. 593, lista 625).

Fols. 239r-240v: diecisiete listas, la mayor parte tomadas de Diqduqé haTe'amim.

Fols. 335v-340v: formado por tres bloques de más de 89 listas: repetición del final de la última lista del apéndice anterior y su continuación, listas con explicaciones midrásicas y listas diversas del libro Oḳlá we-Oḱklá.

Después de comparar detenidamente, tanto los contenidos de estos apéndices, como su forma externa, podemos establecer una serie de características comunes a estos manuscritos:

- Aunque alguno de ellos tiene alguna página destinada a decoración (instrumentos del Templo, etc.), no tienen páginas tapiz.

- Todos ellos tienen masora en forma de micrografía. En general, los diseños son muy sencillos, adoptando todos ellos motivos geométricos. Solamente en el caso de M1 se añade una masora ornamental, mucho más

${ }^{22}$ El texto correspondiente a esta micrografía y su estudio detallado ha sido publicado por M. J. Azcárraga Servert, «Un apéndice ornamental a Reyes en el ms. M1 de la Universidad Complutense de Madrid», Sef 64 (2004), págs. 227-241.

23 Estos apéndices han sido editados por E. Martín Contreras, Apéndices masoréticos. Códice M1 de la Universidad Complutense de Madrid (Madrid 2004).

24 Dada la extensión de estos contenidos, no se detalla aquí cada uno de ellos, remitiéndonos a las dos ediciones citadas. 


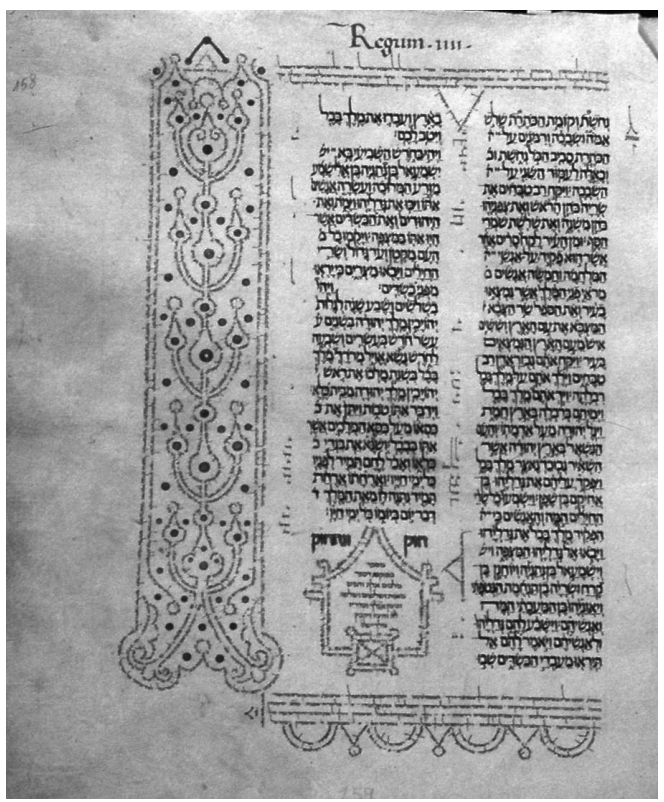

Fig. 10. M1, BUC, fol. 158r.

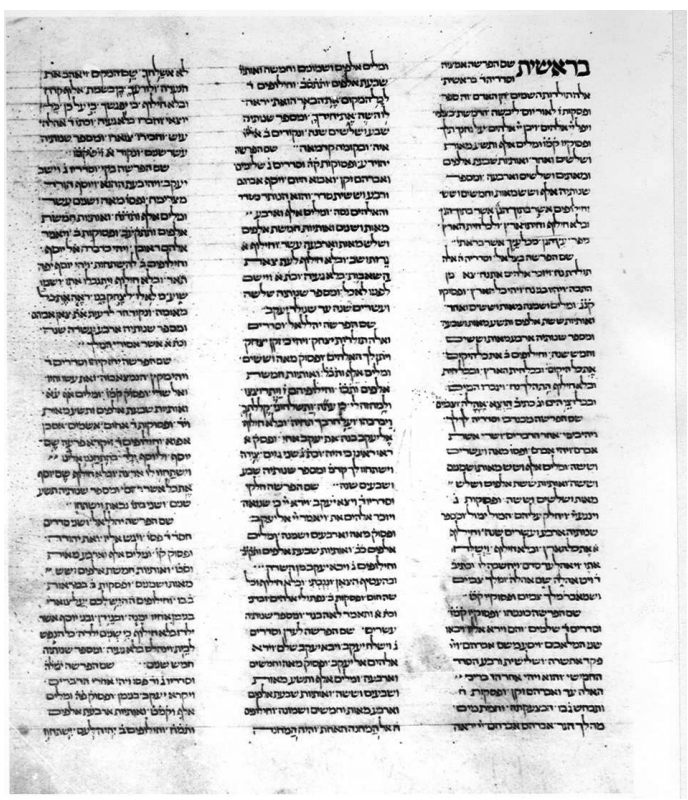

Fig. 11. M1, BUC, fol. 81r. 
abundante en el Pentateuco, en forma de florones, en algunos casos muy elaborada. Estas micrografías contrastan con otros manuscritos españoles, en los que se adoptan muy a menudo formas de candelabro. Estos candelabros no aparecen aquí en ningún otro caso. De hecho, los diseños que presentan son muy similares a los procedentes de la zona oriental. Es decir, así como ya se ha demostrado en otras ocasiones que el texto de los manuscritos españoles, especialmente los toledanos, estaba muy cercano al texto tiberiense, también se puede afirmar que las decoraciones que aparecen en estos manuscritos son herederas de la tradición oriental, en general, mucho menos elaborada que las decoraciones que aparecen en los manuscritos asquenazíes. Podríamos afirmar que los manuscritos escritos en la Península representan, en este sentido, un estadio intermedio entre los manuscritos orientales y los hispanojudíos tardíos o los del resto de Europa, lo cual es fácilmente comprensible debido a las vías naturales de comunicación.

- En la mayoría de los casos, los apéndices de contenido masorético van enmarcados por un rectángulo o cuadrado formado por letras de mayor tamaño, incluso que las del texto bíblico de los manuscritos, rodeado a su vez de otro texto en letra mucho más pequeña. Estos textos suelen ser litúrgicos o también de contenido masorético.

- Solamente en un caso los apéndices masoréticos se escriben ocupando toda la página en tres columnas, con texto seguido, con una letra de menor tamaño que el texto bíblico del manuscrito pero mayor que la de la masora. Esto ocurre en el manuscrito M1.

- En cuanto al contenido de los apéndices, todos los manuscritos consultados coinciden en incluir las listas de sedarim y parašiyyot, en ocasiones solamente del Pentateuco y en ocasiones de todos los libros bíblicos, así como diversos recuentos de versículos. Le sigue en frecuencia de aparición la lista de hil·lufîm Ben Ašer / Ben Naftalí, que se repite en todos los manuscritos excepto en Héb. 25 y Héb. 26. La lista de palabras que vocalizan con patah y llevan atnaḥ o sôf pasîq adquiere una importancia especial, ya que se repite en tres de los manuscritos (Or 2201, Héb. 22 y M1).

Esta lista de palabras que vocalizan con pataḥ y llevan atnaḥ o sôf pasûq falta, además de Héb. 25, en los dos manuscritos del mismo copista (Héb. 26 y Parma 2668). Estos dos manuscritos presentan las listas masoréticas exactamente de la misma forma: en tres columnas, encuadradas por un texto seguido en mayor formato. También son muy similares los contenidos, con excepción de las listas de hilllufîm. Ello se debe probablemente a pertenecer al mismo autor. 
Existe una lista, la de variantes entre orientales y occidentales que solamente aparece en el manuscrito M1, siendo así que es un tipo de información muy frecuente en los manuscritos más conocidos.

El resto de las listas que se recogen en los manuscritos no presentan unidad temática. Se trata de listas de muy diverso contenido, aunque sí podemos afirmar que la mayoría se han podido identificar con listas recogidas en el libro Oḱklá we-Oḱklá, seguido en frecuencia por la Massorah de Ginsburg o en el Diqduqé ha-Te 'amim. Sin embargo, los contenidos de aspecto litúrgico son los más comunes, ya que aparecen en cuatro de los seis manuscritos estudiados. Por otra parte, cada manuscrito parece inclinarse por un aspecto gramatical en sus contenidos: Héb. 25 trata sobre las palabras, Or. 2201 sobre las letras, Héb. 26 sobre versículos, Parma 2668 sobre casos de qěrê / kětîb y solamente M1 presenta una variedad amplia de temas.

\section{CONTENIDOS DE LA MASORA}

Por definición, la masora recoge información masorética, es decir, datos relacionados con el número de veces que aparece una palabra o conjunto de palabras, vocalizaciones, acentuaciones, etc. En otros casos, escasos, puede ser exegética o con otros tipos de información, pero siempre relacionada con el texto bíblico al que corresponde. Pero en algunos casos, el escriba nos puede sorprender incorporando en el espacio destinado a la masora otro tipo de información que nada tiene de masorética. Vamos a ver algunos ejemplos, también en manuscritos españoles.

En el manuscrito Héb. 20 de la BnF, copiado en Tudela en 1300, la masora magna aparece escrita en dos líneas en el margen superior y tres en el inferior y, a menudo, en forma de caligramas que ilustran el texto bíblico correspondiente a ese folio. Los motivos son en muchas ocasiones zoomórficos, como en el caso del fol. 69r. En este caso vemos que hay un dragón en micrografía cuyo contenido es masorético. Pero dentro de sus alas, aparece un colofón, donde especifica que Josué ben Abraham ben Gaón escribió este códice en el mes de marḥešván del año [5]161 (noviembre de 1300). Del mismo modo, en la última línea inferior de esta masora se recoge una bendición: «Bendito sea el que lo copia y bendito el que lo lee, Josué ben Abraham ben Gaón, he escrito esta masora en el año [5]161».

En el mismo manuscrito, en los caligramas de los folios 35r, 177r, 307v, 346r y 361v, entre otros, aparecen notas de alabanzas en hebreo y en arameo. También en los fols. 35v y 40v en el margen derecho se copia parte del comentario de Raší al pasaje correspondiente. Sin embargo, en la mayoría de las oca- 


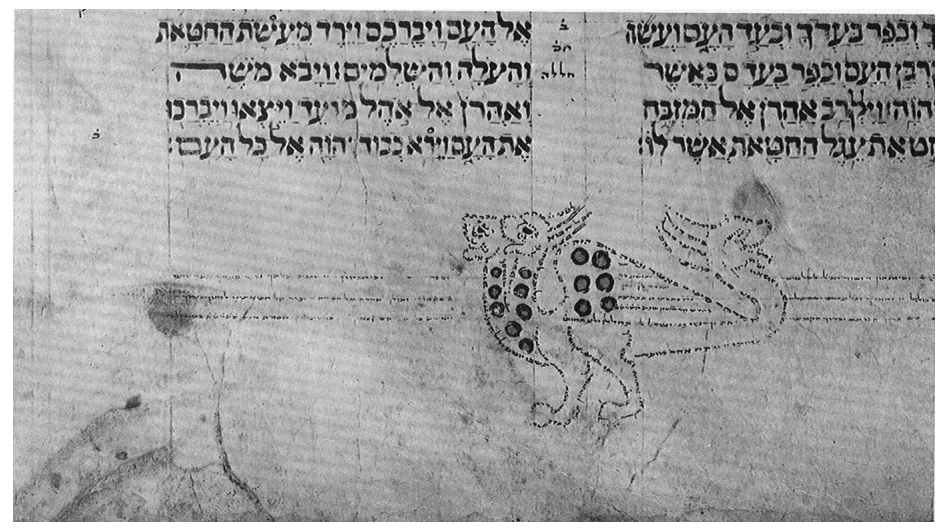

Fig. 12. Héb. 20, BnF, fol. 69r.

siones, los textos que recogen estos caligramas son estrictamente masoréticos, como ocurre en los fols. 254r, donde el dibujo que representa el lobo y el león nombrados en Is 65:25 recoge exclusivamente masora relativa ימלא (Is 65:20), כבקר (Is 65:25), עה אמר יהוה (Is 66:1) y עשתה (Is 66:2). En la serpiente que aparece en el margen interior, se copia la MM sobre la palabra כאחד (Is 65,25). Lo

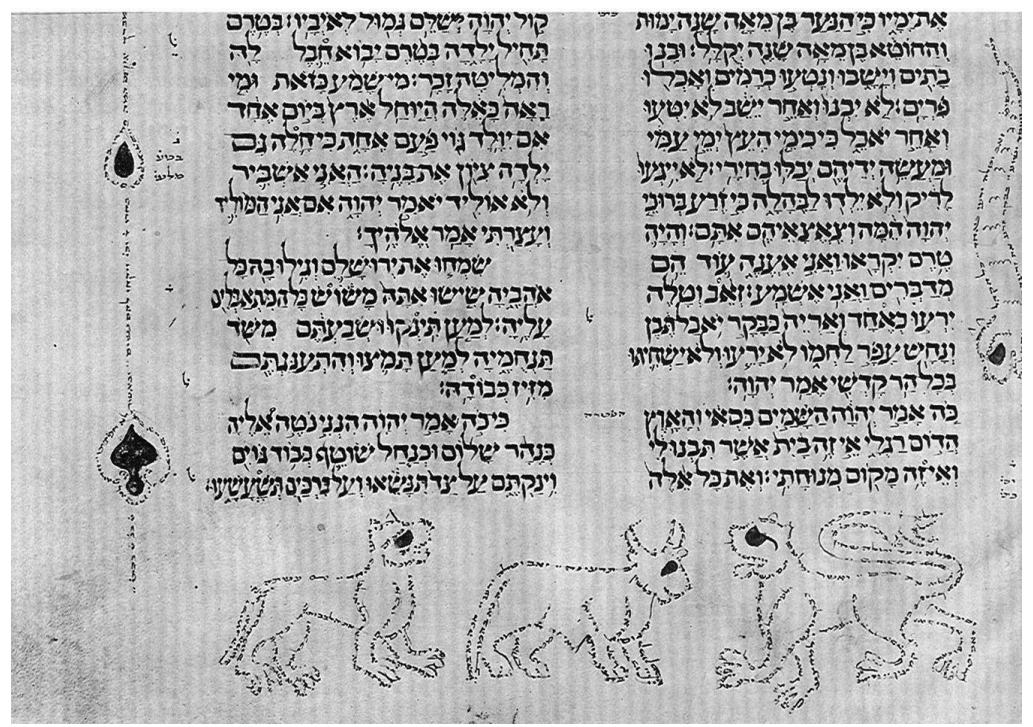

Fig. 13. Héb. 20, BnF, fol. 259r. 
mismo ocurre con la masora que se recoge en los caligramas de los fols. 13r, 16v (Gé 14:7), 17r (Gé 15:9), y el margen inferior del fol 20v (Gé 22:14) donde se dibuja el carnero con sus cuernos enredados.

En otras ocasiones, al contenido masorético se le añade una bendición al escriba, como ocurre en los fols. 91r, 117r, 177r o 326r. En el fol. 45r en el margen inferior hay una micrografía con contenido masorético y añade una bendición bastante larga, que comienza: «Bendito el que escribe y bendito el que lee, por boca del creador, etc.».

Finalmente, a veces se mezclan las informaciones: mientras que el margen superior recoge información masorética, en el margen inferior del fol. 170r se recoge en micrografía el texto de 1 Sam 17:34-36 y un midrás relativo a este texto. En el centro hay un texto rodeando un dibujo de la honda de David que corresponde al texto de 1Sam 17:50.

El manuscrito Héb. 30, una Biblia escrita en Cataluña en 1357, presenta su masora magna escrita en dos líneas en el margen superior y tres en el inferior, con dibujos geométricos generalmente. En ocasiones, también la presenta en forma de micrografías como árboles estilizados o florones en los márgenes exterior e interior del manuscrito, siempre con contenido exclusivamente masorético.

Pero en el fol. 27v, entre los libros de Génesis y Éxodo, aparece un caligrama que representa la cesta donde fue dejado Moisés (Ex 2:3). El texto que se recoge aquí es el de Sal 90:1-9 y 19:1-8. Se trata, en este caso, del único dibujo caligráfico del manuscrito y es de otra mano. El escriba nos ha querido recordar aquí el texto de Salmos donde se recoge la oración de Moisés y la gloria de la Creación y la Ley de Dios. También se recoge un texto de Sal 1:1 en adelante en una micrografía en forma de dos florones que ocupan los márgenes exteriores.

De igual forma, hay otros manuscritos que utilizan el espacio normalmente destinado a la masora para recoger otro tipo de texto. (Foto 15). Por ejemplo, el manuscrito de El Escorial G-I-12, que tiene el texto de Profetas posteriores y Hagiógrafos, en una excelente caligrafía sefardí cuadrada datada entre los siglos XIV-XV, en las tres líneas del margen superior y las cuatro del inferior y hasta el fol. 292, el texto del Sefer ha-Šorašîm de David Qimhí, cuando en realidad en este espacio debería ir la masora magna. El resto del texto del Sefer ha-Šorašîm aparece como texto seguido al final. Lo mismo ocurre también en el manuscrito 1401 del INMH de Jerusalén, fechado en Zaragoza en 1341. El mismo Sefer ha-Šorašîm se recoge en el espacio destinado a la masora magna, desde la letra alef hasta la mem. El resto, desde la mem hasta la taw, aparece en texto seguido al final del texto bíblico. 


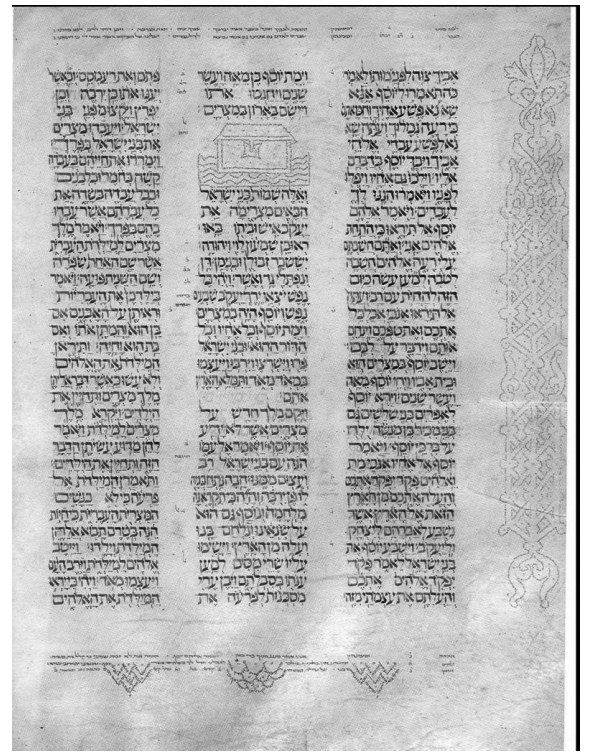

Fig. 14. Héb. 30, BnF, fol. 27v.

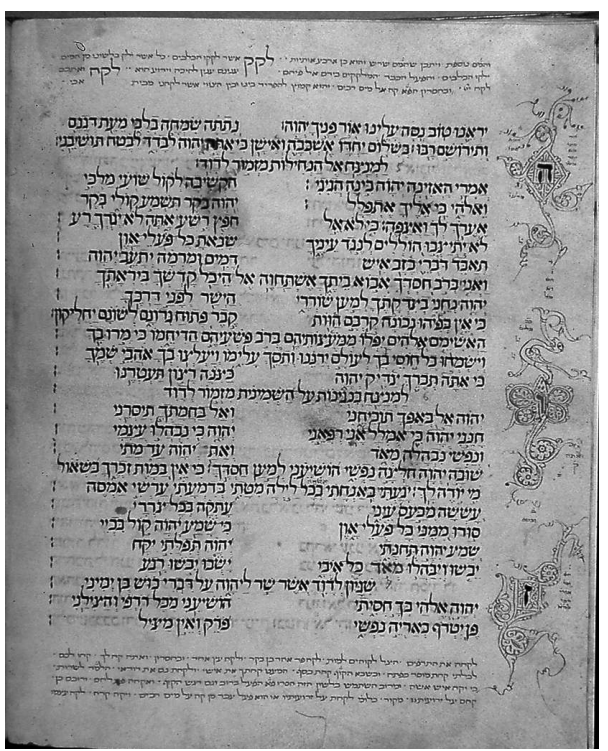

Fig. 15. G-I-12, Biblioteca Monasterio de El Escorial, fol. 130v. 
Este hecho, recoger una información que no tiene que ver con la masora en el espacio destinado a ella, es un hecho ocasional en los manuscritos españoles y que no suele darse en los manuscritos anteriores a 1300. En algunos casos, como hemos visto en el Héb. 30, se trata de una adición posterior. Sin embargo, se trata de un hecho mucho más frecuente en los manuscritos asquenazíes. Es decir, es otra de las características que pueden contribuir a afirmar ese estadio intermedio de desarrollo que supone el conjunto de la producción sefardí entre la tradición oriental y la del resto de Europa, entre la sencillez de decoración de los primeros y las abundantes micrografías de los segundos.

Recibido: $15 / 01 / 2008$

Aceptado: 30/07/2008 